\title{
Desempenho de genótipos de pessegueiros e nectarineiras no oeste de Santa Catarina
}

\author{
Eduardo Cesar Brugnara', Marco Antônio Dalbó e Emilio Della Bruna ${ }^{3}$
}

\begin{abstract}
Resumo - O objetivo deste trabalho foi avaliar o desempenho de genótipos de pessegueiro e nectarineira nas condições do oeste de Santa Catarina. Cinco genótipos de pessegueiro - 'BRS Rubimel', 'Zilli', 'SCS423 Bonora', 'Seleção Epagri 02-40' e 'BRS Fascínio' - e as nectarineiras 'Seleção Epagri 31-43', 'SCS418 Julema' e 'Seleção Embrapa Necta 528' foram avaliados nos municípios de Caibi, Cordilheira Alta (exceto 'BRS Fascínio') e Descanso, até o quarto ano. A colheita de 'Seleção Epagri 31-43', 'SCS418 Julema' e 'SCS423 Bonora' foi mais precoce, com início no segundo decêndio de setembro, apesar da floração um pouco mais tardia em comparação a 'Zilli' e 'BRS Rubimel'. Em termos de produtividade, os destaques foram 'SCS423 Bonora', 'Zilli', 'SCS418 Julema' e 'Seleção Epagri 02-40' em Cordilheira Alta; 'SCS423 Bonora' em Caibi; e 'SCS423 Bonora', 'Zilli' e 'SCS418 Julema' em Descanso. A massa média de frutos foi maior nos tratamentos 'Seleção Epagri 02-40' e 'Zilli' em Cordilheira Alta; 'BRS Fascínio', 'Seleção Epagri 02-40' e 'Zilli' em Caibi; e 'BRS Fascínio' e 'Seleção Epagri 02-40' em Descanso. O pessegueiro 'SCS423 Bonora' e a nectarineira 'SCS418 Julema', dentro do seu grupo, combinam características desejáveis de precocidade, tamanho dos frutos e produtividade.
\end{abstract}

Termos de indexação: Prunus persica; adaptação; precocidade; cultivar.

\section{Performance of peach and nectarine genotypes in the west of Santa Catarina state}

Abstract - The objective of this work was to evaluate the performance of peach and nectarine genotypes in the conditions of western Santa Catarina State. Five peach genotypes ('BRS Rubimel', 'Zilli', 'SCS423 Bonora', 'Seleção Epagri 02-40' and 'BRS Fascínio') and the nectarines 'Seleção Epagri 31-43', 'SCS418 Julema' and 'Seleção Embrapa Necta 528' were evaluated in the municipalities of Caibi, Cordilheira Alta (except 'BRS Fascínio') and Descanso, until the fourth year. The earliest harvest was of 'Seleção Epagri 31-43', 'SCS418 Julema' and 'SCS423 Bonora', starting in the second 10-day period of September, despite the slightly later flowering compared to 'Zilli' and 'BRS Rubimel'. In terms of productivity, the outstanding genotypes were 'SCS423 Bonora', 'Zilli', 'SCS418 Julema' and 'Seleção Epagri 02-40' in Cordilheira Alta, 'SCS423 Bonora' in Caibi and 'SCS423 Bonora', 'Zilli' and 'SCS418 Julema' in Descanso. The average fruit mass was higher in treatments 'Seleção Epagri 02-40' and 'Zilli' in Cordillera Alta, 'BRS Fascínio', 'Seleção Epagri 02-40' and 'Zilli' in Caibi and 'BRS Fascínio' and 'Seleção Epagri 02-40' in Descanso. 'SCS423 Bonora' peach and 'SCS418 Julema' nectarine, inside their group, combine desirable characteristics of precocity, fruit size and productivity.

Index terms: Prunus persica; adaptation; precocity; cultivar.

\section{Introdução}

O pessegueiro (Prunus persica var. vulgaris) e a nectarineira (P. persica var. nucipersica) são plantas frutíferas de clima temperado, que necessitam de frio durante o período hibernal para superar a dormência e terem uma perfeita brotação e floração no final do inverno e início da primavera. O estado de Santa Catarina se caracteriza por apresentar grandes diferenças de acumulo de frio em suas diferentes regiões geográficas. A mesorregião oeste de Santa Catari- na apresenta áreas sob influência do clima subtropical - mesotérmico com verões quentes (Cfa na classificação de Köppen) -, que ocorrem nas proximidades do rio Uruguai, desde o Planalto Sul, e se estendem até a divisa com a Argentina. Nesses locais mais quentes, quando se usa genótipos de baixa exigência de frio, a floração é precoce e a colheita é feita em época anterior às regiões tradicionalmente produtoras da fruta, como a Serra Gaúcha/RS e o Vale do Rio do Peixe/SC, o que pode ser explorado com uma vantagem mercadológica.
Em Santa Catarina, o Zoneamento Agrícola para a cultura do pessegueiro e da nectarineira, para cultivares de baixa exigência de frio, estabelece que são preferenciais as áreas com probabilidade de $80 \%$ ou mais de ocorrência de mais de 150 horas de frio $\leq 7,2^{\circ} \mathrm{C}$ e menos de $20 \%$ de probabilidade de ocorrência de temperatura mínima abaixo de $3^{\circ} \mathrm{C}$ (risco de geada) durante o período de florescimento (EMPRESA DE PESQUISA AGROPECUÁRIA E EXTENSÃO RURAL DE SANTA CATARINA, 2009). Na mesorregião oeste, principalmente

Recebido em 18/05/18. Aceito para publicação em 30/07/18.

http://dx.doi.org/10.22491/RAC.2019.v32n1.10 1 Engenheiro-agrônomo, M.Sc., Empresa de Pesquisa Agropecuária e Extensão Rural (Epagri) de Santa Catarina/Centro de Pesquisa para a Agricultura Familiar (CEPAF), Servidão Ferdinando Tusset, s/n, bairro São Cristóvão, 89801-970, Chapecó, SC, e-mail: eduardobrugnara@epagri.sc.gov.br.

${ }^{2}$ Engenheiro-agrônomo, Ph.D., Epagri/Estação Experimental de Videira, Rua João Zardo, 1660, bairro Campo Experimental, 89560-000, Videira, SC, e-mail: dalbo@epagri.sc.gov.br.

${ }^{3}$ Engenheiro-agrônomo, M.Sc., Epagri/Estação Experimental de Urussanga, Rodovia SC 108 - Km 353, 1563, bairro Estação, 88840-000, Urussanga, SC, e-mail: emilio@epagri.sc.gov.br. 
no vale do Rio Uruguai, existem áreas preferenciais para o cultivo dessas frutíferas.

A substituição dos cultivares em uso por novos, oriundos de mutações e de programas de melhoramento, depende da superioridade do novo em relação ao padrão. Essa superioridade, no caso da região em questão, pode ser dada pela precocidade de colheita, pois proporciona preços de venda maiores que os da época normal, desde que a qualidade da fruta e a produtividade sejam satisfatórias. Nesse sentido, o objetivo deste trabalho foi avaliar o desempenho produtivo de cultivares de lançamento recente e seleções promissoras de pessegueiro e nectarineira oriundas dos programas de melhoramento genético da Empresa de Pesquisa Agropecuária e Extensão Rural de Santa Catarina (Epagri) e da Empresa Brasileira de Pesquisa Agropecuária (Embrapa) com baixa exigência de frio nas condições de clima Cfa da região oeste de Santa Catarina.

\section{Material e métodos}

Foram executados três experimentos em três municípios catarinenses: Caibi $\left(-27^{\circ} 6,488^{\prime} ;-53^{\circ} 19,707^{\prime} ; 329 \mathrm{~m}\right.$ de altitude), Descanso $\left(-26^{\circ} 48,821^{\prime}\right.$; $\left.-53^{\circ} 27,846^{\prime} ; 503 \mathrm{~m}\right)$ e Cordilheira Alta (-2657,824'; -52³9,891'; 469 m), nos quais o clima é do tipo Cfa. Foram delineados em blocos casualizados com quatro repetições de quatro plantas. Os tratamentos foram os genótipos (cultivares e seleções) de pessegueiro 'BRS Rubimel', 'Zilli', 'SCS423 Bonora', 'Seleção Epagri 02-40' e 'BRS Fascínio', e os de nectarineira 'Seleção Epagri 31-43', 'SCS418 Julema' e 'Seleção Embrapa Necta 528'. As seleções Epagri são oriundas do programa de melhoramento genético da Epagri (Estação Experimental de Urussanga) e a 'Seleção Embrapa Necta 528', do programa da Embrapa.

O plantio foi realizado em agosto de 2013, em espaçamento de $5 \times 1,3 \mathrm{~m}$. O sistema de condução adotado foi o " $Y$ ", com uma poda seca em junho e de duas a três podas verdes ao longo do ciclo. As correções de acidez do solo e fertilizações foram feitas conforme as recomendações para a cultura (SOCIEDADE BRASILEIRA DE CIÊNCIA DO SOLO, 2004; FREIRE; MAGNANI, 2014). O manejo fi- tossanitário foi realizado com auxílio de pulverizações de inseticidas, acaricidas e fungicidas registrados para a cultura. Não foram empregadas técnicas para quebra de dormência ou abscisão de foIhas no outono.

Foram levantados junto ao Centro de Informações de Recursos Ambientais e de Hidrometeorologia de Santa Catarina (Ciram) dados de horas de frio abaixo de $7,2^{\circ} \mathrm{C}$ e de temperatura máxima e mínima diária do ar para as estações de Caibi (369 m de altitude e distante do experimento cerca de $9 \mathrm{~km}$ ), São Miguel do Oeste (700 $\mathrm{m}$ de altitude e distante do experimento de Descanso cerca de 6 km) e Chapecó (687 m de altitude e distante cerca de $12 \mathrm{~km}$ do experimento de Cordilheira Alta).

De 2015 a 2017 foram registrados o início e o final da floração em cada parcela por meio de visitas periódicas espaçadas de sete a dez dias. O critério utilizado para início de floração foi a predominância de ramos com flores abertas, e para fim de floração, a predominância de ramos com flores em queda de pétalas ou já com frutos. Foi realizado o raleio, deixando-se um fruto a cada $10 \mathrm{~cm}$ de ramo ou somente um nos ramos finos. Os frutos raleados foram contados. A produção de 2014 a 2017 foi avaliada pela contagem e pesagem dos frutos maduros. Os números de frutos raleados e colhidos foram somados para estimar a fixação de frutos, o que é um indicador da adaptação do genótipo, pois depende do número de gemas floríferas, de flores abertas e frutificação efetiva. De 2015 a 2017 foram medidas as circunferências dos troncos das plantas para caracterizar o seu crescimento e capacidade de produção.

Para cada experimento foram feitas análises de variância e testes de Duncan $(\alpha=0,05)$ para as médias dos tratamentos nas variáveis: soma de frutos raleados e colhidos, massa de frutos colhidos, massa média de frutos e área da secção do tronco. Com as variáveis número de frutos colhidos, frutos raleados, massa de frutos colhidos, massa média de frutos e área da seç̧ão do tronco, foram analisados os componentes principais para avaliar as relações entre as variáveis.

\section{Resultados e discussão}

A Figura 1 ilustra os decêndios quando a floração dos diferentes genótipos ocorreu, nos três locais e nos três anos. Em Caibi, a floração mais precoce, considerando os três anos, foi a dos genótipos 'BRS Rubimel', 'Zilli' e 'Seleção Epagri 31-43', seguidos por 'SCS423 Bonora' e 'SCS418 Julema'. Em Descanso, a floração mais precoce foi do 'BRS Rubimel', seguido pelo 'Zilli'. A 'Seleção Epagri 31-43' foi o genótipo mais precoce em Cordilheira Alta, seguido pelo 'Zilli'. O 'BRS Fascínio' foi o mais tardio: em Descanso sua floração se estendeu até setembro. Como os genótipos 'BRS Ru-

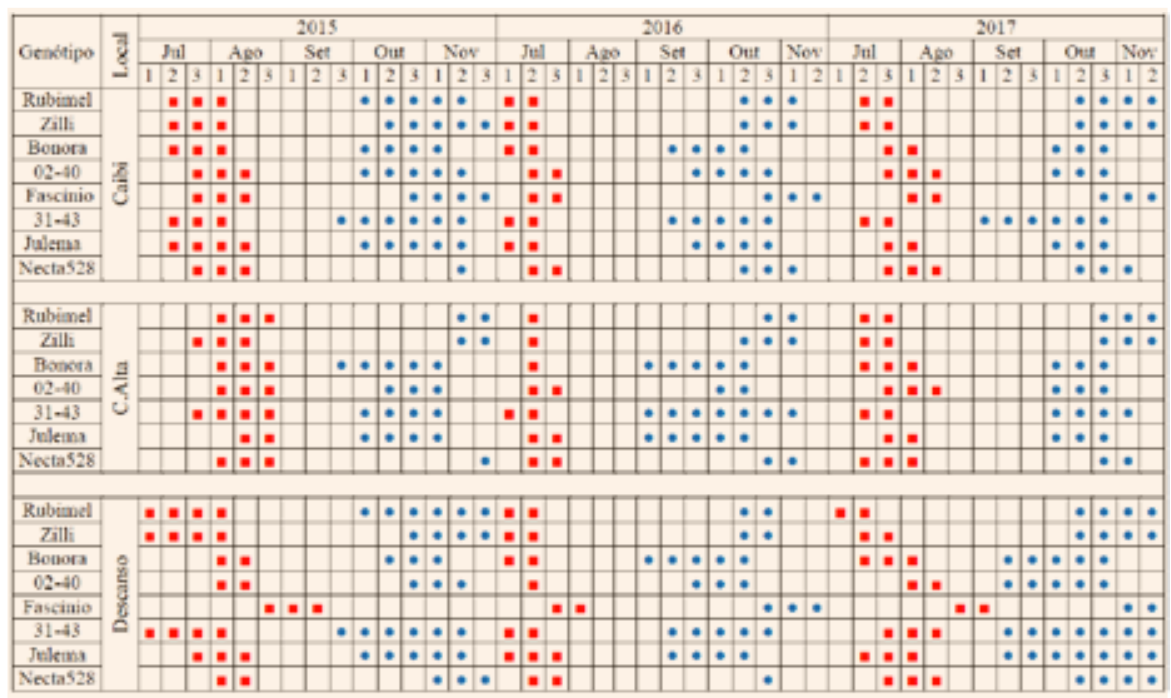

Figura 1 - Decêndios de floração $(\square)$ e colheita $(\bullet)$ de diferentes genótipos de pessegueiro e nectarineira em Caibi, Cordilheira Alta e Descanso, do terceiro ao quinto ciclo de crescimento (2015 a 2017).

Figure 1 - Flowering and harvesting times of different genotypes of peach and nectarine in Caibi, Cordilheira Alta and Descanso, from third to fifth growth cycle (2015 to 2017) 
bimel' e 'BRS Fascínio' têm necessidade de frio semelhante, é provável que o segundo exija maior tempo térmico para a floração. A necessidade de frio para quebra de dormência e a de calor para a saída da dormência (ecodormência) são genótipo-dependentes (CITADIN et al., 2001; CITADIN et al., 2002), enquanto a disponibilidade de frio e de calor variam entre locais e anos (NIENOW \& FLOSS, 2002). Isso pode explicar as diferenças da época de floração entre genótipos no mesmo local e de um mesmo genótipo em vários locais.

A época de colheita variou entre os genótipos (Figura 1). Destacaram-se pela maior precocidade os de nectarineira 'Seleção Epagri 31-43' e 'SCS418 Julema' e o pessegueiro 'SCS418 Bonora'. 'Zilli' e 'BRS Rubimel' apresentaram maturação mais tardia, apesar da sua precocidade de floração. Isso aconteceu porque o tempo necessário para completar o ciclo da frutificação é variável entre genótipo (SOUZA et al., 2011). A colheita do 'Seleção Epagri 31-43' ao longo dos anos e locais destacou-se pelo seu longo período: começou entre o início de setembro e o início de outubro, dependendo do ano e local, e se estendeu por 40 a 60 dias. O 'BRS Fascínio' foi o genótipo mais tardio, com colheita a partir do segundo decêndio de outubro até o segundo de novembro, frequentemente acompanhado por 'Zilli' e 'BRS Rubimel', este levemente mais precoce.

A área de secção do tronco (AST) medida no quarto ano foi maior em Caibi e menor em Descanso para todos os genótipos (Tabela 1). O destaque de crescimento foi o 'SCS423 Bonora', que atingiu em Caibi $137,3 \mathrm{~cm}^{2}$, e o 'Zilli' e o 'BRS Rubimel' foram os de menor crescimento. Entretanto, a AST não apresentou relação com a produção de frutos (Figura 2), ou seja, a produção global dos experimentos não foi limitada pelo crescimento das plantas. Os números de frutos colhidos e o de raleados relacionaram positivamente com a massa de frutos colhida, ou seja, as diferenças de produção entre genótipos se devem à sua capacidade de emitir frutos em cada ambiente.

O somatório do número de frutos colhidos e raleados é uma forma de estimar a frutificação efetiva, considerando que ocorrem algumas perdas não controladas. Os valores observados

Tabela 1 - Área de secção do tronco, soma de frutos colhidos e raleados e massa média dos frutos de diferentes genótipos de pessegueiro e nectarineira em três locais de Santa Catarina

Table 1 - Trunk section area, sum of harvested and thinned fruits and average mass of fruits of different peach and nectarine genotypes in three locations of Santa Catarina

\begin{tabular}{|c|c|c|c|c|c|c|c|c|}
\hline & \multicolumn{5}{|c|}{ Pessegueiros } & \multicolumn{3}{|c|}{ Nectarineiras } \\
\hline & $02-40$ & Bonora & Fascínio & Rubimel & Zilli & $31-43$ & Julema & $\begin{array}{c}\text { Necta } \\
528\end{array}$ \\
\hline & \multicolumn{8}{|c|}{ Área se secção do tronco no $4 \stackrel{0}{ }$ ano $\left(\mathrm{cm}^{1}\right)$} \\
\hline Cordilheira Alta & $93,7 a^{(2)}$ & 91,4 a &.$^{(3)}$ & $56,2 b$ & $58,0 \mathrm{~b}$ & $80,7 \mathrm{ab}$ & 98,1 a & $79,7 a b$ \\
\hline Caibi & $126,2 \mathrm{ab}$ & 137,3 a & $112,3 \mathrm{bc}$ & $77,0 \mathrm{~d}$ & $78,5 d$ & $97,4 \mathrm{~cd}$ & $125,1 \mathrm{ab}$ & $101,9 \mathrm{c}$ \\
\hline \multirow[t]{2}{*}{ Descanso } & $63,0 \mathrm{ab}$ & 74,3 a & $56,1 b$ & $39,2 \mathrm{~cd}$ & $35,8 \mathrm{~d}$ & $56,2 b$ & $73,1 \mathrm{a}$ & 53,2 bc \\
\hline & \multicolumn{8}{|c|}{ Frutos colhidos + raleados $^{(1)}\left(n-\right.$ planta $\left.^{-1}\right)$} \\
\hline Cordilheira Alta & $55,9 a b$ & 86,6 a & . & $46,0 \mathrm{bc}$ & 84,8 a & $29,4 \mathrm{~cd}$ & $48,9 \mathrm{bc}$ & $15,3 d$ \\
\hline Caibi & 24,5 ef & $87,2 \mathrm{bc}$ & $15,2 \mathrm{f}$ & $131,2 \mathrm{~b}$ & 294,3 a & 47,5 cde & $57,7 \mathrm{~cd}$ & 35,9 de \\
\hline \multirow[t]{2}{*}{ Descanso } & $39,0 \mathrm{bcd}$ & 78,8 a & 25,6 de & $44,9 \mathrm{bcd}$ & $61,1 \mathrm{ab}$ & $37,4 \mathrm{~cd}$ & $57,3 \mathrm{bc}$ & 19,9 e \\
\hline & \multicolumn{8}{|c|}{ Massa média dos frutos ${ }^{(1)}\left(\mathrm{g}\right.$ fruto $\left.^{-1}\right)$} \\
\hline Cordilheira Alta & $92,3 \mathrm{ab}$ & $78,8 \mathrm{~b}$ & . & $85,1 \mathrm{bc}$ & 101,6 a & $62,9 d$ & $71,1 \mathrm{~cd}$ & $57,8 d$ \\
\hline Caibi & $96,9 a b$ & $78,6 \mathrm{c}$ & 98,3 a & $88,5 \mathrm{~b}$ & $92,0 a b$ & 57,5 e & $73,8 \mathrm{c}$ & $65,6 d$ \\
\hline Descanso & $78,4 \mathrm{ab}$ & $65,5 \mathrm{bc}$ & 96,3 a & $70,1 \mathrm{~b}$ & $72,8 \mathrm{~b}$ & $51,0 d$ & $65,4 \mathrm{bc}$ & $55,9 \mathrm{~cd}$ \\
\hline
\end{tabular}

(1) Média dos quatro anos de avaliação. (2) Médias seguidas pela mesma letra na linha não diferem estatisticamente (Teste de Duncan, $\alpha=0,05$ ); (3) Parcelas perdidas

nos experimentos foram maiores para o tratamento 'Seleção Epagri 02-40' em Cordilheira Alta, 'SCS423 Bonora' em Descanso e Cordilheira Alta e para o 'Zilli' nos três locais. A planta fixou 294,3 frutos ao longo dos quatro anos em Caibi, em média, valor significativamente maior que o dos demais tratamentos. As diferenças entre genótipos na quantidade de frutos fixados são devidas às diferenças em porcentagem de brotação de gemas vegetativas do ano anterior (que afetam o número de ramos de produção) e das gemas floríferas daqueles ramos, além de taxa de frutificação efetiva (HAWERROTH et al., 2009; MODESTO et al., 2014).

A massa total de frutos colhidos dos genótipos em cada local e ano é apresentada na Tabela 2. Já no segundo ciclo de crescimento após o plantio, as plantas apresentaram produção de 0,02 a $2,54 \mathrm{~kg}$, com destaque para o local Caibi, no qual 'SCS423 Bonora' e 'SCS418 Julema' produziram mais de $2 \mathrm{~kg}$ por planta, em média. A maior produção em Caibi, no primeiro ano, se deveu ao maior crescimento das plantas (Tabela 1) naquele local, que provavelmente resultou em mais ramos de produção. Houve aumento da produtividade das plantas até o quarto ano (2016), seguido por uma queda em 2017. A tendên- cia de aumento anual se deve ao crescimento das plantas, e foi modificada provavelmente pelo menor acúmulo de frio no ano de 2017 em relação a 2016. Em 2016, em Cordilheira Alta, quando se registrou maior acúmulo de frio, observaram-se as maiores produtividades (até $11,84 \mathrm{~kg}$ por planta no tratamento 'Zilli') (Tabela 2), o que reforça a importância do frio na produção.

O número de horas de frio $\leq 7,2^{\circ} \mathrm{C}$ acumuladas em Caibi foi de 41 em 2015, de 234 em 2016 e de 102 em 2017; em São Miguel do Oeste (referente a Descanso), foi de 47 em 2015, de 275 em 2016 e de 28 em 2017; em Chapecó (referente à Cordilheira Alta), foi de 67 em 2015, de 314 em 2016 e de 105 em 2017. Deve ser considerado que a altitude das estações meteorológicas de Chapecó e São Miguel do Oeste é maior que a dos locais onde estão instalados os experimentos correspondentes, o que significa que as plantas foram expostas a menos horas de frio do que as registradas. A necessidade de baixa temperatura dos genótipos 'SCS423 Bonora' e 'Zilli' é de 200 h, do 'BRS Rubimel' e do 'BRS Fascínio' é de 200 a 300 h e do 'SCS418 Julema' é de 150 h (DALBÓ \& LORO, 2012; DELLA BRUNA et al., 2013; DELLA BRUNA et al., 2017; RASEIRA et al., 2014). Portanto, nos anos de 2015 e 


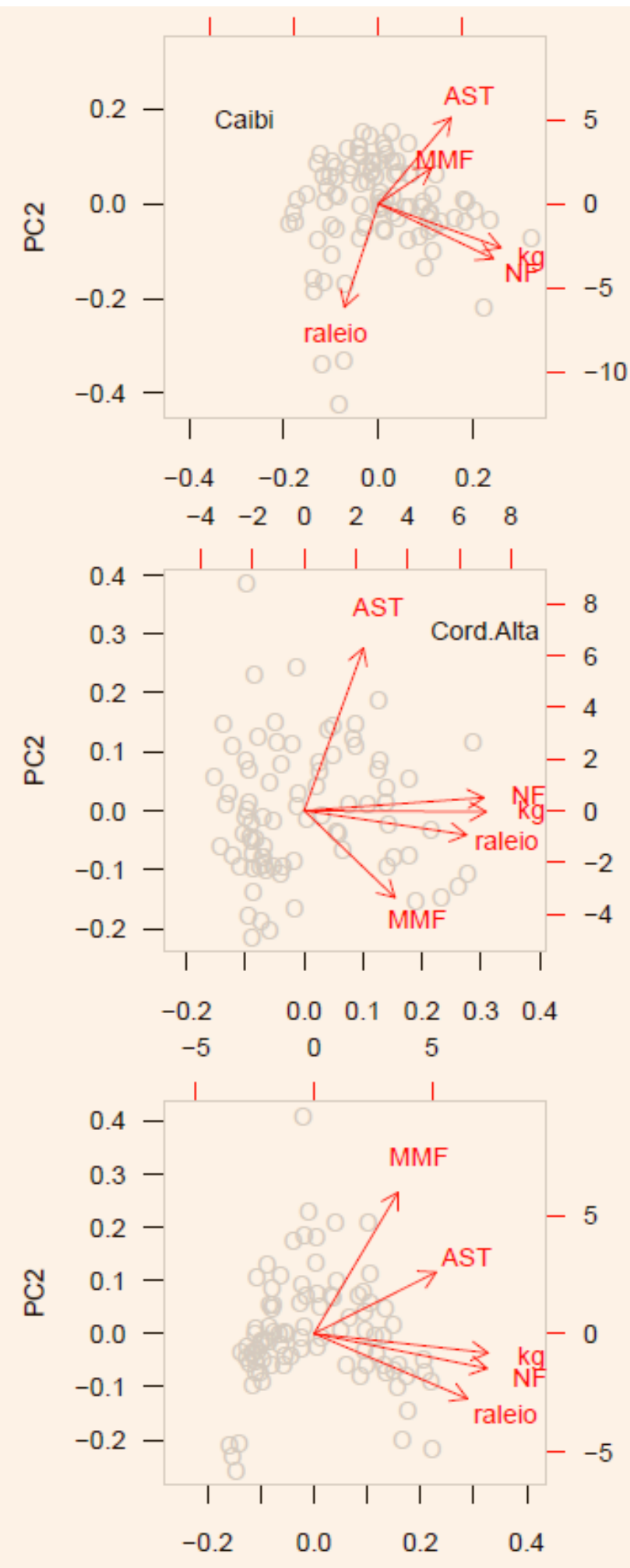

Figura 2-Gráficos biplot representando as análises de componentes principais das variáveis massa de frutos (kg); número de frutos colhidos (NF) e raleados (raleio); massa média de frutos (MMF); e área da secção do tronco (AST), avaliadas de 2015 a 2017 em três locais (Caibi, Cordilheira Alta e Descanso). Figure 2 - Biplot graphs representing the principal component analysis of the variables mass of fruits $(\mathrm{kg})$; number of fruits harvested (NF) and thinned (raleio); mean fruit mass (MMF); and trunk section area (AST), evaluated from 2015 to 2017 at three sites (Caibi, Cordilheira Alta and Descanso)
2017, as exigências de frio dos genótipos testados não foram atendidas.

As produtividades observadas (Tabela 1) foram relativamente baixas se compararmos às relatadas por Gonçalves et al. (2014), equivalente a $12,78 \mathrm{~kg}$ planta- $^{-1}$ (média do quarto e quinto anos), em Pelotas/RS, com espaçamento 1,5 × 5,0 m e podas de inverno e verão. Porém, mesmo cultivares considerados adaptados à região, como 'Zilli', apresentaram desempenho ruim, o que pode estar relacionado à idade das plantas, manejo, ocorrência de frio hibernal (discutido anteriormente) e temperaturas altas durante a floração. Já Rocha et al. (2007) observaram que o 'Chimarrita', do qual se originou o 'Zilli', produziu $810 \mathrm{~g}$ planta-1 ${ }^{-1}$ no terceiro ano (média de cinco portaenxertos), o que é inferior ao observado neste trabalho, no terceiro ano, para 'SCS423 Bonora', 'SCS418 Julema', 'BRS Rubimel' e 'Zilli'. Além de frio insuficiente e da idade das plantas, as temperaturas altas que ocorrem no oeste de Santa Catarina desde a saída de dormência até a polinização podem reduzir a polinização e a fixação de frutos, resultando em baixa produtividade (KOZAl et al., 2004; NAVA, 2007).

A média anual da massa de frutos colhidos apresentou diferenças significativas entre genótipos nos três locais (Tabela 2). Em Caibi, o 'SCS423 Bonora' foi o genótipo significativamente mais produtivo, com média de $3,94 \mathrm{~kg}$ planta ${ }^{-1} \mathrm{ano}^{-1}$, seguido por 'SCS418 Julema' e 'Zilli'. Em Cordilheira Alta, os genótipos 'SCS423 Bonora', 'SCS418 Julema', 'Zilli' e 'Seleção Epagri 02-40' não diferiram entre si, com médias de produtividade de 3,14 a 4,26 kg planta-1 ano $^{-1}$. Em Descanso houve superioridade do 'SCS423 Bonora', do 'SCS418 Julema' e do 'Zilli'. O genótipo 'Seleção Embrapa Necta 528' teve sempre a menor média observada, de 0,8 a 1,04 kg planta ${ }^{-1}$ ano $^{-1}$.

Houve diferenças significativas na massa média dos frutos de alguns genótipos (Tabela 1). Em Cordilheira Alta o 'Zilli' apresentou a maior média, não diferindo significativamente apenas do 'Seleção Epagri 02-40'. O 'BRS Fascínio', em Caibi, apresentou média significativamente maior que 'Seleção Epagri 31-43', 'SCS423 Bonora', 'SCS418 Julema', 'Seleção Embrapa Necta 528' e 'BRS Rubimel'. Já em Descanso o 'BRS Fascínio' superou todos os tratamentos menos o 'Seleção Epagri 02-40'. Independentemente do local em análise, a massa média dos frutos não teve relação com o número de colhidos (Figura 2), o que significa que a carga de frutos após o raleio esteve dentro da capacidade das plantas em fornecer nutrientes para o seu crescimento. A massa média também não teve correlação com a massa total colhida. Isso significa que a produção foi dependente do número de frutos restantes após o raleio.

Diante das informações apresentadas, sugere-se a continuidade das avaliações nas plantas adultas, bem como estudos da fisiologia da floração e frutificação diante das condições climáticas da região.

\section{Conclusão}

O pessegueiro 'SCS423 Bonora' se destaca por precocidade de colheita, produtividade e tamanho de frutos; a 'SCS418 Julema', por ser a nectarineira com maior produtividade e boa precocidade de colheita; e, ainda, o 'Zilli' e a 'Seleção Epagri 02-40', pela produtividade moderada e maior massa média de frutos. 
Tabela 2 - Produção de frutos (colhidos) de diferentes genótipos de pessegueiro e nectarineira em Caibi, Cordilheira Alta e Descanso, do segundo ao quinto ciclo de crescimento (2014 a 2017)

Table 2 - Fruit yield (harvested) of different peach and nectarine genotypes in Caibi, Cordilheira Alta and Descanso, from second to fifth growth cycle (2014 to 2017)

\begin{tabular}{|c|c|c|c|c|c|c|c|c|}
\hline \multicolumn{6}{|c|}{ Pessegueiros } & \multicolumn{3}{|c|}{ Nectarineiras } \\
\hline Anos & $02-40$ & Bonora & Fascínio & Rubimel & Zilli & $31-43$ & Julema & $\begin{array}{c}\text { Necta } \\
528\end{array}$ \\
\hline \multicolumn{9}{|c|}{ Cordilheira Alta (kg planta ${ }^{-1}$ ) } \\
\hline 2014 & 0,37 & 0,31 &.$(2)$ & 0,06 & 0,04 & 0,02 & 0,24 & 0,01 \\
\hline 2015 & 0,64 & 1,03 & . & 0,54 & 0,71 & 0,18 & 0,14 & 0,00 \\
\hline 2016 & 10,77 & 10,57 & . & 9,57 & 11,84 & 6,07 & 8,26 & 3,21 \\
\hline 2017 & 3,85 & 5,15 & . & 1,35 & 2,2 & 0,25 & 3,93 & 0,47 \\
\hline Média & $3,91 a b^{(1)}$ & 4,26 a & . & $2,88 \mathrm{~b}$ & $3,70 \mathrm{ab}$ & $1,62 \mathrm{c}$ & $3,14 a b$ & $0,92 \mathrm{~d}$ \\
\hline \multicolumn{9}{|c|}{ Caibi (kg planta ${ }^{-1}$ ) } \\
\hline 2014 & 0,13 & 2,54 & 0,19 & 0,34 & 0,41 & 0,77 & 2,12 & 0,14 \\
\hline 2015 & 0,27 & 4,89 & 0,33 & 1,59 & 2,29 & 0,74 & 2,35 & 0,26 \\
\hline 2016 & 6,69 & 4,32 & 2,38 & 3,99 & 5,11 & 2,99 & 5,12 & 2,62 \\
\hline 2017 & 1,19 & 4,01 & 1,7 & 1,34 & 2,31 & 2,14 & 1,08 & 0,18 \\
\hline Média & $2,07 \mathrm{bc}$ & $3,94 \mathrm{a}$ & $1,15 \mathrm{~d}$ & $1,81 \mathrm{c}$ & $2,53 \mathrm{~b}$ & $1,66 \mathrm{c}$ & $2,67 b$ & $0,80 d$ \\
\hline \multicolumn{9}{|c|}{ Descanso (kg planta-1) } \\
\hline 2014 & 0,03 & 0,59 & 0,03 & 0,36 & 0,1 & 0,05 & 0,14 & 0,01 \\
\hline 2015 & 0,18 & 0,87 & 0 & 0,42 & 0,37 & 0,58 & 0,35 & 0,17 \\
\hline 2016 & 5,9 & 5,8 & 5,34 & 6,86 & 6,72 & 4,03 & 5,92 & 2,95 \\
\hline 2017 & 2,17 & 5,56 & 1,66 & 0,4 & 2,08 & 1,27 & 3,66 & 1,05 \\
\hline Média & $2,07 \mathrm{bc}$ & $3,21 \mathrm{a}$ & $1,76 \mathrm{bcd}$ & $2,01 \mathrm{bc}$ & $2,32 \mathrm{abc}$ & $1,48 \mathrm{~cd}$ & $2,52 a b$ & $1,04 \mathrm{~d}$ \\
\hline
\end{tabular}

\section{Agradecimentos}

À Financiadora de Estudos e Projetos (Finep) e à Fundação de Amparo à Pesquisa e Inovação do Estado de Santa Catarina (Fapesc).

\section{Referências}

CITADIN, I.; RASEIRA, M.C.B.; HERTER, F.G. Heat requirement for blooming and leafing in peach. Hortscience, Alexandria, v. 36, n. 2, p. 305-307, 2001. Disponível em: <https:// bit.ly/2NyxshU>. Acesso em: 20 dez. 2017.

CITADIN, I.; RASEIRA, M.C.B.; HERTER, F.G.; SILVEIRA, C.A.P. Avaliação da necessidade de frio em pessegueiro. Revista Brasileira de Fruticultura, Jaboticabal, v.24, n.3, p.703706, 2002.

DALBÓ, M.A.; LORO, L.J. ZILLI - Nova cultivar de pessegueiro produtora de frutos com polpa bicolor. In: CONGRESSO BRASILEIRO DE FRUTICULTURA, 22., 2012, Bento Gonçalves. Anais... Bento Gonçalves: Sociedade Brasileira de Fruticultura, 2012.
DELLA BRUNA, E.D.; MORETO, A.L.; DALBÓ, M.A.; PETRY, H.B. SCS423 Bonora: um novo cultivar de pessegueiro. Agropecuária $\mathrm{Ca}$ tarinense, Florianópolis, v.30, n.2, p.54-56, 2017.

DELLA BRUNA, E.D.; MORETO, A.L.; DALBÓ, M.A. SCS 418 Julema: novo cultivar de nectarina adaptado a regiões com baixo frio hibernal. Florianópolis: Epagri, 2013. 2p.

EMPRESA DE PESQUISA AGROPECUÁRIA E EXTENSÃO RURAL DE SANTA CATARINA. Pêssego (Proagro): Zoneamento Agrícola considerando os riscos climáticos para a cultura do Pêssego. EPAGRI/CIRAM, Florianópolis, 24 abr. 2009. Disponível em: <https://bit.ly/2NzObTJ>. Acesso em: 26 out. 2017.

FREIRE, C.J.; MAGNANI, M. Adubação e correção do solo. In.: RASEIRA, M.C.B.; PEREIRA, J.F.M.; CARVALHO, F.L.C. (Eds.) Pessegueiro. Brasília: Embrapa, 2014. p. 259-281.

GONÇALVES, M.A.; PICOLOTTO. L.; AZEVEDO, F.Q.; COCCO, C.; ANTUNES, L.E.C. Qualidade de fruto e produtividade de pessegueiros submetidos a diferentes épocas de poda. Ciência Rural, Santa Maria, v.44, n.8, p.1334-1340, 2014.

HAWERROTH, F.J.; PETRI, J.L.; LEITE, G.B.; HERTER, F.G.; MARAFON, A.C. Efeito do frio e do desponte na brotação de gemas em pessegueiro. Revista Brasileira de Fruticultura, Jaboticabal, v.31, n.2, p.440-446, 2009.

KOZAI, N.; BEPPU, K.; MOCHIOKA, R.; BOONPRAKOB, U; SUBHADRABANDHU, S.; KATAOKA, I. Adverse effects of high temperature on the development of reproductive organs in 'Hakuho' peach trees. Journal of Horticultural Science and Biotechnology, Ashford, v.79, n.4, p.533-537, 2004.

MODESTO, J.H.; VEDOATO, B.T.F.; LEONEL, S. TECCHIO, M.A. Crescimento vegetativo, fenologia, produção e sazonalidade dos frutos de pessegueiros e nectarineira. Magistra, Cruz das Almas, v.23, n.3, p.420-426, 2014. Disponível em: <https://bit.ly/2CJ8GaQ>. Acesso em: 22 fev. 2018.

NAVA, G.A. Desenvolvimento floral e frutificação de pessegueiros [Prunus persica (L.) Batsch] cv. Granada, submetidos a distintas condições térmicas durante o período de pré-floração e floração. 2007. 158 f. Tese (Doutorado em Fitotecnia) - Faculdade de Agronomia, Universidade Federal do Rio Grande do Sul, Porto Alegre, 2007.

NIENOW, A.A.; FLOSS, L.G. Floração de pessegueiros e nectarineiras no planalto médio do Rio Grande do Sul, influenciada pelas condições meteorológicas. Ciência Rural, Santa Maria, v.32, n.6, p.931-936, 2002.

RASEIRA, M.C.B.; NAKASU, B.H.; BARBOZA, W. Cultivares: descrição e recomendação. In.: RASEIRA, M.C.B.; PEREIRA, J.F.M.; CARVALHO, F.L.C. (Eds.) Pessegueiro. Brasília: Embrapa, 2014. p. 73-141.

ROCHA, M.S.; BIANCHI, V.J.; FACHINELLO, J.C.; SCHMITZ, J.D.; PASA, M.S.; SILVA, J.B. Comportamento agronômico inicial da cV. Chimarrita enxertada em cinco porta-enxertos de pessegueiro. Revista Brasileira de Fruticultura, Jaboticabal, v.29, n.3, p.583588, 2007.

SOCIEDADE BRASILEIRA DE CIÊNCIA DO SOLO. Comissão de Química e Fertilidade do Solo. Manual de adubação e de calagem para os Estados do Rio Grande do Sul e de Santa Catarina. 10. ed. Porto Alegre: Sociedade Brasileira de Ciência do Solo, 2004. p. 102.

SOUZA, A.P.; LEONEL, S.; SILVA, A.C. Basal temperature and thermal sum in phenological phases of nectarine and peach cultivars. Pesquisa Agropecuária Brasileira, Brasília, v.46, n.12, p.1588-1596, 2011. 